\title{
The Problem of the Negation of the Conditional
}

\author{
Miguel López-Astorga \\ Institute of Humanistic Studies "Juan Ignacio Molina", University of Talca, Chile. Email address: \\ milopez@utalca.cl
}

Received August 25, 2016; Revised December 16, 2016; Accepted December 30, 2016; Published January 14, 2017

\begin{abstract}
People usually seem to negate the conditional in a different way as it is provided by standard logic. Both contemporary experimental results and texts coming from ancient sources appear to demonstrate that individuals tend not to negate the conditionals in entirety, but only their consequents. Obviously, this can lead one to think that there is no relationship between standard logic and human language and reasoning. However, in this paper, I try to show that, in spite of the mentioned results and texts, it is possible to continue to accept that there are certain links between systems such as that of Gentzen and the way people often negate the conditionals. That way is not, in many cases, exactly the one required by standard logic, but it is not absolutely inconsistent with the latter either.
\end{abstract}

Keywords: conditional; logical form; negation; standard logic; syntax

\section{Introduction}

Following standard logic, one might think that the correct way to negate a conditional such as 'If $\mathrm{p}$ then q' is 'It is not true that if $\mathrm{p}$ then q'. However, there is evidence that people do not usually negate the conditionals in that way. It is more common that a conditional such as that indicated is denied as 'If $\mathrm{p}$ then not-q', that is, not negating the entire conditional, but only its then-clause. That evidence is to be found in several works, some of them authored by contemporary researchers and the other ones written by ancient philosophers and logicians (especially, Aristotle and Boethius). In addition, it can be said that different current cognitive theories that, in principle, seem to be absolutely incompatible, for example, the mental models theory (e.g., Johnson-Laird, 2012, 2015; Khemlani, Orenes, \& Johnson-Laird, 2012, 2014; Ragni, Sonntag, \& Johnson-Laird, 2016) and the mental logic theory (e.g., Braine \& O'Brien, 1998a; O'Brien, 2009, 2014; O'Brien \& Li, 2013), completely agree that, indeed, most of the people often negate the conditionals just negating their consequents (see, e.g., for the mental models theory, Khemlani et al., 2014, p. 4, Table1; and, for the mental logic theory, O’Brien, 2014, p. 229).

Undoubtedly, this is a problem from the standard logic point of view, since it reveals that its logical forms and the definitions, equivalences, and relationships that it provides for those forms may have nothing to do with human language and thought, and that, therefore, calculi such as the one of Gentzen (1935) have no link to our syntactic constructions. But my aim here is to try to show that this is not necessarily so. True, the mentioned texts indicate that individuals do not often negate the conditionals in the exact way that could be expected from standard logic. Nonetheless, their negations of the conditionals are not clearly inconsistent with Gentzen's (1935)

(C) AesthetixMS 2016. This Open Access article is published under a Creative Commons Attribution Non-Commercial 4.0 International License (http://creativecommons.org/licenses/by-nc/4.o/), which permits non-commercial re-use, distribution, and reproduction in any medium, provided the original work is properly cited. For citation use the DOI. For commercial re-use, please contact editor@rupkatha.com. 
calculus either, which means that it is justified to continue to think that there is a relationship of any kind between standard logic and the human mind.

To argue in favor of this idea, I will firstly explain why, under the framework of standard logic, it is a problem that the conditionals are denied just denying their then-clauses. Then, I will comment on the evidence proving the fact that people truly only negate the consequents of the conditionals, both that presented in the current cognitive science literature and that raised by ancient texts. Finally, I will show that that evidence is not totally incompatible with systems such as the one of Gentzen and that hence the thesis of a relationship between standard logic and the human intellectual activity cannot be completely rejected yet.

\section{The problem}

Certainly, in standard logic it is not suitable to deny a conditional putting the negation only in the consequent. A conditional such as 'If $\mathrm{p}$ then q' has the logical form $[\mathrm{p} \rightarrow \mathrm{q}$ ] (where ' $\rightarrow$ ' stands for conditional relationship), and the best way to negate it is not using the formula [p $\rightarrow \neg q$ ] (where ' $\neg$ ' represents the negation), but by means of the formal structure $[\neg(p \rightarrow q)]$.

This is so because $[\neg(p \rightarrow q)]$ is the real contrary of $[p \rightarrow q]$, and not $[p \rightarrow \neg q]$. Indeed, assuming that ' $v$ ' refers to the truth value of the formula following between brackets, that ' 1 ' means 'true', and that 'o' represents 'false', it can be said that, as it is well known,

$\mathrm{v}(\mathrm{p} \rightarrow \mathrm{q})=\mathrm{o}$ if and only if $\mathrm{v}[\neg(\mathrm{p} \rightarrow \mathrm{q})]=1$.

The reason of this is that, as it is also well known,

$\mathrm{v}(\mathrm{p} \rightarrow \mathrm{q})=\mathrm{o}$ if and only if $\mathrm{v}(\mathrm{p})=1$ and $\mathrm{v}(\mathrm{q})=\mathrm{o}$. In all of the other cases, $\mathrm{v}(\mathrm{p} \rightarrow \mathrm{q})=1$. Conversely, $\mathrm{v}[\neg(\mathrm{p} \rightarrow \mathrm{q})]=1$ if and only if $\mathrm{v}(\mathrm{p})=1$ and $\mathrm{v}(\mathrm{q})=0$. In all of the other cases, $\mathrm{v}[\neg(\mathrm{p} \rightarrow \mathrm{q})]=0$.

So, as said, it can be stated that both formulae are clearly opposite.

But this is not the relationship that exists between $[\mathrm{p} \rightarrow \mathrm{q}]$ and $[\mathrm{p} \rightarrow \neg \mathrm{q}]$. There are two cases in which these two last formulae can be true at the same time: the two cases in which $\mathrm{v}(\mathrm{p})=\mathrm{o}$. True,

If, on the one hand, $v(p)=o$ and $v(q)=1$, or, on the other hand, $v(p)=o$ and $v(q)=o$, then, given that, as stated, a conditional is false only when its antecedent is true and its consequent is false, both $\mathrm{v}(\mathrm{p} \rightarrow \mathrm{q})=1$ and $\mathrm{v}(\mathrm{p} \rightarrow \neg \mathrm{q})=1$ (a similar explanation is to be found, e.g., in López-Astorga, 2016a, pp. 22-23).

$[\mathrm{p} \rightarrow \mathrm{q}]$ and $[\mathrm{p} \rightarrow \neg \mathrm{q}]$ are not hence contrary, which means in turn that $[\neg(\mathrm{p} \rightarrow \mathrm{q})]$ and $[\mathrm{p} \rightarrow \neg \mathrm{q}]$ are not equivalent and that one of them cannot be replaced by the other one. Certainly, as just explained, [p $\rightarrow \neg q]$ is true both when [p] is false and [q] is true and when [p] is false and [q] is false, and, in those same cases, as also indicated, $[\neg(p \rightarrow q)]$ is false.

However, as also mentioned, both the contemporary cognitive science literature and ancient sources seem to show that the human mind considers [p $\rightarrow \neg q]$ and $[\neg(p \rightarrow q)]$ to be equivalent. I comment on some examples in this regard in the next section.

\section{The negation of the conditional as a negation of its second clause}

The contemporary evidence comes from different cognitive approaches. Nevertheless, to the goals of this paper, just a couple of examples can be enough. One of them, which is very illustrative, is 
that provided by Khemlani et al. (2014). They carried out two experiments with thematic content and the first one included a condition in which participants were asked to select, between four combinations of possibilities corresponding to the structures A and B, A and not-B, not-A and B, and not-A and not-B, the one(s) which a denied conditional with the logical form $[\neg(\mathrm{p} \rightarrow \mathrm{q})]$ referred to. $59 \%$ of participants responded that the accurate combinations were A and not-B, notA and B, and not-A and not-B (see Khemlani et al., 2014, p. 4, Table 1), that is, if the explanation of the previous section is taken into account, the combinations in which $\mathrm{v}(\mathrm{p} \rightarrow \neg \mathrm{q})=1$ (obviously, such combinations are those related to the cases $\mathrm{v}(\mathrm{p})=1$ and $\mathrm{v}(\mathrm{q})=\mathrm{o}, \mathrm{v}(\mathrm{p})=\mathrm{o}$ and $\mathrm{v}(\mathrm{q})=1$, and $\mathrm{v}(\mathrm{p})=\mathrm{o}$ and $\mathrm{v}(\mathrm{q})=\mathrm{o}$ respectively). Only $14 \%$ of them selected just the combination $\mathrm{A}$ and not-B (Khemlani et al., 2014, p. 4, Table 1), that is, paying attention again to the explanation above, the only combination in which actually $\mathrm{v}[\neg(\mathrm{p} \rightarrow \mathrm{q})]=1$ (obviously, that combination is the one related to the case $\mathrm{v}(\mathrm{p})=1$ and $\mathrm{v}(\mathrm{q})=\mathrm{o})$.

In a second experiment, which used thematic content too, the instructions were directly to deny a conditional such as 'If A then B', and, while $28 \%$ of participants answered correctly 'No, A and not-B', 34\% of them only negated the consequent and gave as a response 'No, if A then not B' (Khemlani et al., 2014, p. 5, Table 2).

On the other hand, from a different point of view, based on experimental results as well, O'Brien says "...both children and adults will infer that if $p$ then $q$ is false when the supposition of $p$ leads to a derivation of not- $q$, ..." (O'Brien, 2014, p. 229; italics in text). Evidently, what O'Brien wants to state is that a naïve individual without logical background does not understand the conditional in a material way, that is, in the way usually assigned to Philo of Megara, which is precisely the one assumed by Gentzen's (1935) natural deduction system and, accordingly, by standard logic (see, e.g., Bocheński, 1963, p. 89; López-Astorga, 2016a, pp. 23-24; Mates, 1953, p. 44; O'Brien, 2014, pp. 222ff; O'Toole \& Jennings, 2004, p. 479). This is so because, following that interpretation, $[\neg(p \rightarrow q)]$ cannot be drawn from $[p \rightarrow \neg q]$. The reason has already been accounted for: when $\mathrm{v}(\mathrm{p})=\mathrm{o}, \mathrm{v}(\mathrm{p} \rightarrow \neg \mathrm{q})=1$ and $\mathrm{v}[\neg(\mathrm{p} \rightarrow \mathrm{q})]=\mathrm{o}$.

But there are also ancient texts that suggest equivalence between these two last formulae

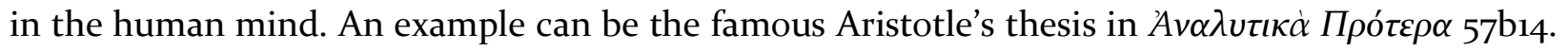
As it is well known, that thesis has two versions:

$[\mathrm{AT} 1] \neg(\neg \mathrm{p} \rightarrow \mathrm{p})$

$[\mathrm{AT} 2] \neg(\mathrm{p} \rightarrow \neg \mathrm{p})$

The fact that, although neither $\left[\mathrm{AT}_{1}\right]$ nor $\left[\mathrm{AT}_{2}\right]$ are tautologies, Aristotle admitted them as obvious theses has been studied in several papers from different perspectives (e.g., López-Astorga, 2013, 2016b; Pfeifer, 2012). However, what is interesting here is that the acceptance of this thesis appears to suppose the equivalence between $[\neg(p \rightarrow q)]$ and $[p \rightarrow \neg q]$ too. Indeed, if this equivalence is assumed, $\left[\mathrm{AT}_{1}\right]$ can be transformed into this tautology:

$\neg \mathrm{p} \rightarrow \neg \mathrm{p}$

And $\left[\mathrm{AT}_{2}\right]$ into this one:

$\mathrm{p} \rightarrow \neg \neg \mathrm{p}=\mathrm{p} \rightarrow \mathrm{p}$

A last example can be the one that is to be found in Boethius' De Syllogismo Hypothetico. In particular, the example refers to this inference (see also, e.g., López-Astorga, 2016a, p. 21; McCall, 1966, p. 415; O'Toole \& Jennings, 2004, p. 482, Note 140): 
$\mathrm{p} \rightarrow(\mathrm{q} \rightarrow \mathrm{r})$

$\mathrm{q} \rightarrow \neg \mathrm{r}$

So, $\neg \mathrm{p}$

The problematic character of this deduction has been analyzed in several works as well (see, e.g., the same references in the previous brackets). Nevertheless, what is relevant for this paper is that it also seems to accept the equivalence. True, if $[q \rightarrow \neg r$ ] is considered to be equivalent to $[\neg(q \rightarrow$ r)], the following inference is possible in standard propositional calculus:
[1] $\mathrm{p} \rightarrow(\mathrm{q} \rightarrow \mathrm{r})$
(premise)
$[2] \mathrm{q} \rightarrow \neg \mathrm{r}$
(premise)
[3] $\neg(\mathrm{q} \rightarrow \mathrm{r})$
(equivalence 2)
$[4] \neg \mathrm{p}$
(Modus Tollendo Tollens 1, 3)

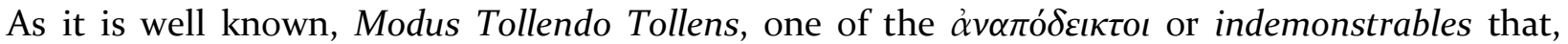
according to Diogenes Laërtius (Vitae Philosophorum 7, 8o), was identified by Chrysippus of Soli, is valid in standard logic and enables infer [ $\neg$ p] from premises such as [p $\rightarrow q]$ and $[\neg q]$. The problem with this inference is hence only step [3], since it needs the equivalence that, as explained, is not really admissible in standard logic.

However, in my view, all of this does not mean that it is clear that systems such as that of Gentzen (1935) should be ignored in the studies about reasoning and language. Neither the contemporary experimental results nor facts such as those that can be found in the ancient sources commented on lead us necessarily to a rejection of standard logic. The relationships between such results and facts and this last logic are not difficult to see, and I develop this point below.

\section{The evidence supporting a negation of just the consequent and Gentzen's calculus}

A first interesting point about Khemlani et al.'s (2014) research is that not all their participants provided the equivalence. In fact, the numbers are clearer in an experiment (the first one) than in the other one. This is important because shows that, while it is true that there are many people that deny the conditionals negating only their second clause, it is also true that not all of them do so, and that a relevant number of individuals can interpret the negated conditionals in the sense required by standard logic.

Nevertheless, apart from that, it is possible to see links to standard logic even in the responses given by the participants that negate $[\mathrm{p} \rightarrow \mathrm{q}]$ as $[\mathrm{p} \rightarrow \neg \mathrm{q}]$. As mentioned, in that logic, $[\neg(\mathrm{p} \rightarrow \mathrm{q})]$ and $[\mathrm{p} \rightarrow \neg \mathrm{q}]$ are not equivalent. Nonetheless, both formulae are related at least to some extent: although $[\neg(\mathrm{p} \rightarrow \mathrm{q})]$ cannot be derived from $[\mathrm{p} \rightarrow \neg \mathrm{q}]$, it is possible to deduce the latter from the former. Maybe it is trivial, but I present a way to do that deduction as an illustration:
$[1] \neg(\mathrm{p} \rightarrow \mathrm{q})$
(premise)
[2] $\mathrm{p}$
(supposition)
[3] $\mathrm{p} \wedge \neg \mathrm{q}$
(from 1) 


$$
\begin{array}{ll}
{[4] \neg \mathrm{q}} & \text { (elimination of the conjunction 3) } \\
{[5] \mathrm{p} \rightarrow \neg \mathrm{q}} & \text { (introduction of a conditional 2-4) }
\end{array}
$$

Where ' $\wedge$ ' represents conjunction.

Step [3] is justified because, as said, $\mathrm{v}[\neg(\mathrm{p} \rightarrow \mathrm{q})]=1$ if and only if $\mathrm{v}(\mathrm{p})=1$ and $\mathrm{v}(\mathrm{q})=\mathrm{o}$. So, $[\neg(\mathrm{p} \rightarrow$ $q)$ ] is equivalent to [p $\wedge \neg q$ ], which, obviously, is also true if and only if $v(p)=1$ and $v(q)=0$. Step [4] consists of the application of a basic rule in standard logic: from [p $\wedge \mathrm{q}$ ] can be derived both [p] and [q]. Finally, step [5] is the application of a essential rule in that very logic too: if [p] is supposed and $[\mathrm{q}]$ is drawn, $[\mathrm{p} \rightarrow \mathrm{q}]$ can be concluded.

But the most important point now is that the experiments carried out by Khemlani et al. (2014) are both of them in this direction, that is, from $[\neg(p \rightarrow q)]$ to $[p \rightarrow \neg q]$, and not vice versa. This is so because, in the two cases, $[\neg(p \rightarrow q)]$ is provided at the beginning and a number of participants come to $[\mathrm{p} \rightarrow \neg \mathrm{q}$ ] (notice that, in one of them, the participants are asked to indicate the possibilities corresponding to $[\neg(\mathrm{p} \rightarrow \mathrm{q})]$, and, in the other one, what this last formula actually means). As explained, that is not absolutely correct, since these two formulae are not equivalent, but, as also shown, there is at least a possible deduction in standard propositional calculus that allows concluding $[\mathrm{p} \rightarrow \neg \mathrm{q}]$ from $[\neg(\mathrm{p} \rightarrow \mathrm{q})]$, which clearly reveals that it cannot be said that there is no possible relationship between the answers given by Khemlani et al.'s (2014) participants and standard logic. There is a logical link between the sentence provided in the instructions and the final result even in the case of the participants that thought that a denied conditional is a conditional in which only the consequent is negated.

This can help understand what happens with Aristotle's thesis as well. In its two versions, the initial formula enables the deduction of a tautology, since, although [AT1] and [ $\neg \mathrm{p} \rightarrow \neg \mathrm{p}]$, and [AT2] and $[\mathrm{p} \rightarrow \mathrm{p}]$, are not equivalent, $[\neg \mathrm{p} \rightarrow \neg \mathrm{p}]$ can be deduced from [AT1], and [p $\rightarrow \mathrm{p}$ ] from [AT2], in a similar way as in the previous inference. Therefore, while the process is not totally correct, as there is not a clear equivalence, it cannot be stated that standard logic is not present at least in a way.

However, the case of O'Brien's (2014) arguments is different. He does not speak about a process from $[\neg(p \rightarrow q)]$ to $[p \rightarrow \neg q]$, but about exactly the inverse process, from [p $\rightarrow \neg q]$ to $[\neg(p$ $\rightarrow$ q)], and, as said, the latter cannot be drawn from the former in a system such as that of Gentzen (1935). Nevertheless, this does not mean that a relationship to standard logic cannot be found here. If we come back to O'Brien's words, it is clear that he thinks about a situation in which $[\neg q]$ has been deduced in a scenario in which [p] has been supposed to be true, and in such a scenario it does be possible to derive $[\neg(\mathrm{p} \rightarrow \mathrm{q})]$. For example, let us consider a scenario in which the premise $[\neg p \vee \neg q]$, where ' $\vee$ ' represents disjunction, is true. In that scenario, if [p] is supposed to be true, $[\mathrm{p} \rightarrow \neg \mathrm{q}]$ can be drawn in this way:
[1] $\neg \mathrm{p} \vee \neg \mathrm{q}$
(premise)
[2] $\mathrm{p}$
(assumption)
$[3] \neg \mathrm{q}$
(Modus Tollendo Ponens 1, 2)
[4] $\mathrm{p} \rightarrow \neg \mathrm{q}$
(introduction of a conditional 2-3)

Of course, Modus Tollendo Ponens, which allows deducing [q] from premises such as [p $\vee \mathrm{q}$ ] and $[\neg \mathrm{p}]$, and is also an $\dot{\alpha} v \alpha \pi \hat{\delta} \delta \varepsilon \kappa \tau o \varsigma$ provided by Chrysippus (Diogenes Laërtius, Vitae Philosophorum 
$7,81)$, is another valid rule in standard calculus. But what is relevant in this inference is that [p] can continue to be supposed to be true and more formulae can be deduced, for instance:

[5] $\mathrm{p} \rightarrow \mathrm{q}$

[6] q

[7] $\mathrm{q} \wedge \neg \mathrm{q}$

$[8] \neg(\mathrm{p} \rightarrow \mathrm{q})$ (supposition)

(Modus Ponendo Ponens 2, 5)

(introduction of a conjunction 6,3)

(Reductio ad Absurdum 5-7)

Here, one more Chrysippus' 'à $\alpha \pi \delta ́ \delta \varepsilon ı \kappa \tau o \varsigma$ is used. That is Modus Ponendo Ponens and enables to infer the consequent of a conditional from that very conditional and its antecedent, that is, to infer [q] from formulae such as [p $\rightarrow$ q] and [p] (see Diogenes Laërtius, Vitae Philosophorum 7 , 80 ). On the other hand, the conjunction introduction rule is applied in step [7]. By virtue of it, two formulae such as, for example, [p] and [q] can be linked in a formula such as $[\mathrm{p} \wedge \mathrm{q}]$. Finally, Reductio ad Absurdum procedure, which allows concluding the negation of a supposition, in this case, the negation of [p $\rightarrow \mathrm{q}]$, that is $\neg[\mathrm{p} \rightarrow \mathrm{q}]$, if a contradiction such as the one of step [7] is

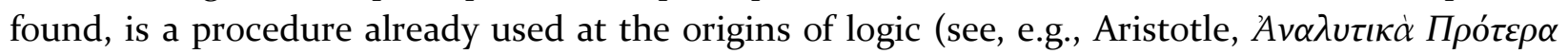
B14, 62b29-38; Boger, 2004, p. 228). But what is important about this is that, as it is well known, these rules are also absolutely valid in standard propositional calculus, which reveals that, according to that calculus, in a scenario in which it is possible to deduce [ $\neg \mathrm{q}]$ after taking [p] as an assumption, it is possible, if [p] continues to be considered to be true, to derive $[\neg(p \rightarrow q)]$ as well.

Thus, although $[\neg(\mathrm{p} \rightarrow \mathrm{q})]$ cannot be really inferred from $[\mathrm{p} \rightarrow \neg \mathrm{q}]$, it is clear, however, that, in a scenario in which both $[\mathrm{p} \rightarrow \neg \mathrm{q}]$ and $[\mathrm{p}]$ are true, it does be possible to draw $[\neg(\mathrm{p} \rightarrow \mathrm{q})]$. And this circumstance is the one that can lead one to link a formula such as [p $\rightarrow \neg q$ ] to a formula such as $[\neg(p \rightarrow q)]$. In this way, it can be thought that what happens is that people usually think about actually possible scenarios, and that, given that, most of the time, [p $\rightarrow \neg q]$ is only actually possible when [p] is true, in most of the contexts in which [p $\rightarrow \neg q]$ is true, $[\neg(p \rightarrow q)]$ can be derived too. And this is what causes individuals to consider these two formulae to be equivalent.

Of course, it is also possible that some individuals realize that such equivalence is not correct. The previous paragraph describes a situation in which people make little effort, and it is obvious that an individual thinking carefully about the formulae $[\mathrm{p} \rightarrow \neg \mathrm{q}]$ and $[\neg(\mathrm{p} \rightarrow \mathrm{q})]$ can note that the former alone does not really enable to infer the latter. This possibility can be supported at least from two points of view. Firstly, as indicated, the percentages obtained by Khemlani et al. (2014) in their experiments show that some individuals may come to understand the real meanings and the differences between a negated conditional and a positive conditional in which only its then-clause is negated. Secondly, theories such as that of the mental logic propose the existence of sophisticated individuals that can have better logical skills (see, e.g., Braine \& O'Brien, 1998b, p. 223; López-Astorga, 2015a, pp. 2off). Evidently, such individuals can be aware that the two mentioned formulae do not provide exactly the same.

Nevertheless, in spite of this, it is obvious that the previous explanation clarifies why many people tend to interpret the conditionals in the way indicated by O'Brien (2014). Likewise, it enables to understand the reasons why many individuals consider the inference presented by Boethius, which, as indicated above, also appears to require a transformation of [p $\rightarrow \neg q]$ into $[\neg(p \rightarrow q)]$, to be valid. As said, because [p $\rightarrow \neg q]$ is often true in scenarios in which [p] is so as well, and in those scenarios $[\neg(\mathrm{p} \rightarrow \mathrm{q})]$ can be derived too, they think that $[\mathrm{p} \rightarrow \neg \mathrm{q}]$ and $[\neg(\mathrm{p} \rightarrow$ q)] are equivalent and hence that Boethius' inference is correct. Nonetheless, if, as also 
commented on, a sophisticated individual can note that those formulae are not the same, does this mean that a philosopher such as Boethius was not logically sophisticated? Of course, the answer to this question is negative. Boethius could accept his inference for technical reasons. This point is explained in the last section.

\section{Conclusions}

Really, it is very probable that human reasoning does not follow standard logic, or, at least, that it does not follow standard logic alone. Current theories such as the mentioned ones in this paper (the mental models theory and the mental logic theory) reject this idea. In this way, my aim here has not been to demonstrate the opposite. My only goal has been to show that, in spite of certain evidence coming from contemporary experimental researches and ancient texts, it cannot be said that a system such as that of Gentzen (1935) has nothing to do with the human intellectual activity.

The case reviewed has been that of the negation of the conditionals and, as argued, the results obtained by Khemlani et al. (2014) and the Aristotle's thesis indicated are not actually a problem for standard logic. In this last logic, [p $\rightarrow \neg q]$ can be drawn from $[\neg(p \rightarrow q)]$, and this is consistent with both Khemlani et al.'s (2014) results and the Aristotle's thesis.

As far as O'Brien's (2014) arguments and Boethius' inference are concerned, the situation is different. In both of these cases, the transformation needed seems to be the inverse, that is, the transformation from $[p \rightarrow \neg q]$ to $[\neg(p \rightarrow q)]$. As explained, that derivation is not admitted by standard calculus. However, it can be assumed that many people consider those two formulae to be equivalent because, as also accounted for, in many scenarios, [p $\rightarrow \neg q$ ] can be deduced only when $[p]$ is supposed, and, in those same scenarios, $[\neg(p \rightarrow q)]$ can be inferred too.

The problem here is, as also commented on, that, given that there can be sophisticated individuals that are able to note that the formulae are not actually equivalent, one might think that important logicians in the history of philosophy such as Boethius were not really logically sophisticated thinkers. Nevertheless, this does not have to be so. A usual mistake is to interpret ancient logics based on standard logic (for arguments in this sense for Stoic logic, see, e.g., Bobzien, 1996, p. 134; or López-Astorga, 2016c, p. 22) and maybe those logics require to be understood in their contexts. Thus, in the particular case of Boethius' inference, it can be thought, as held by McCall (1966), that Boethius did not accept Philo's interpretation of the conditional, but that he assumed Chrysippus' criterion of it, which is to be found in many texts written by both ancient and contemporary authors (e.g., Cicero, De Fato 12; Diogenes Laërtius, Vitae Philosophorum 7, 73; Sextus Empiricus, Pyrrhoniae Hypotyposes 2, 111; Barnes, Bobzien, \& Mignucci, 2008, p. 107; Gould, 1970, p. 76; López-Astorga, 2015b, p. 9, 2016d, pp. 66-67; Mueller, 1978, p. 20; O'Toole \& Jennings, 2004, p. 479). Based on them, it can be stated that, following Chrysippus of Soli, a conditional is only correct when the denial of its then-clause is in contradiction with its if-clause. This means that it is necessary that there is a relationship between the clauses such that the negation of the second one implies the negation of the first one. In this way, if this criterion of the conditional, which, as it is well known, is often called 'the connexivist interpretation', is also attributed to Boethius, it is evident that he could admit his inference at the same time. If the conditionals [p $\rightarrow \mathrm{q}$ ] and [p $\rightarrow \neg q]$ fulfill the criterion, both [q] and [ $\neg \mathrm{q}]$ are in contradiction with [p], which shows that both conditionals are in contradiction with each other as well, and that, therefore, it is justified that one of them implies the negation of the other one 
(McCall, 1966, pp. 145-146; see also, e.g., López-Astorga, 2016a, p. 25; O’Toole \& Jennings, 2004, p. 482, Note 140).

So, it can be claimed that Boethius proposed his inference because he had a technical definition of the conditional that was other than the one of Philo of Megara, or, if preferred, of standard logic, and not because he did not make enough cognitive effort or was not a sophisticated logician. Furthermore, it is clear that the interests and the goals corresponding to ancient logics were very different from those of current logicians, cognitive science theorists, or linguists. Thus, it can be said that we have no evidence that ancient logics tried to describe human reasoning or the actual way human beings understand sentences. They offered frameworks explaining the characteristics that a correct inference had to have. They did not show what individuals really do when faced to an inference. Accordingly, that Boethius thought that his inference is valid is not a problem. It is perfectly understandable if his general context is taken into account. And the same can be stated with regard to any other ancient logic, including, of course, the Aristotelian one, which presents theses or arguments inconsistent with standard logic.

A different problem that does need to be accounted for is the fact that a naive (without logical background) individual considers Boethius' inference to be correct, since that can be interpreted, as mentioned, as a proof that people do not interpret the conditionals in the same way as standard logic. Nonetheless, as also said, in this paper an explanation of that fact has been presented, which is that people often base their answers and ideas on results obtained in similar situations, and, because $[p \rightarrow \neg q]$ and $[\neg(p \rightarrow q)]$ are both of them valid at the same time in many situations, individuals can tend to the idea that they provide the same relationship between [p] and [q]. Two clear conclusions can be derived from all of this. On the one hand, it appears that a deeper level of logic and linguistics in the educational systems can be very positive, since it can lead to a better understanding of what a denied conditional truly means. On the other hand, it also seems that the calculus proposed by Gentzen (1935) is not absolutely separated from the human mind, and that, as suggested, for instance, in López-Astorga (2015c), there are underlying logical forms in our language that are, at least to some extend, compatible with that calculus.

\section{References}

Barnes, J., Bobzien, S., \& Mignucci, M. (2008). Logic. In K. Algra, J. Barnes, J. Mansfeld, \& M. Schofield (Eds.), The Cambridge History of Hellenistic Philosophy (pp. 77-225). Cambridge, UK: Cambridge University Press.

Bobzien, S. (1996). Stoic syllogistic. In C. C. W. Taylor (Ed.), Oxford Studies in Ancient Philosophy (pp. 133192). Oxford, UK: Clarendon Press.

Bocheński, I. M. (1963). Ancient Formal Logic. Amsterdam, The Netherlands: North-Holland.

Boger, G. (2004). Aristotle's underlying logic. In D. M. Gabbay \& J. Woods (Eds.), Handbook of the History of Logic, Volume 1. Greek, Indian and Arabic Logic (pp. 101-246). Amsterdam, The Netherlands: Elsevier.

Braine, M. D. S. \& O’Brien, D. P. (Eds.) (1998a). Mental Logic. Mahwah, NJ: Lawrence Erlbaum Associates, Inc., Publishers.

Braine, M. D. S. \& O'Brien, D. P. (1998b). A theory of if: A lexical entry, reasoning program, and pragmatic principles. In M. D. S. Braine \& D. P. O’Brien (Eds.), Mental Logic (pp. 199-244). Mahwah, NJ: Lawrence Erlbaum Associates, Inc., Publishers.

Gentzen, G. (1935). Untersuchungen über das logische Schließen I. Mathematische Zeitschrift, 39, 176-210.

Gould, J. B. (1970). The Philosophy of Chrysippus. Albany, NY: State University of New York Press. 
Johnson-Laird, P. N. (2012). Inference with mental models. In K. J. Holyoak \& R. G. Morrison (Eds.), The Oxford Handbook of Thinking and Reasoning (pp. 134-145). New York, NY: Oxford University Press.

Johnson-Laird, P. N. (2015). How to improve thinking. In R. Wegerif, L. Li, \& J. C. Kaufman (Eds.), The Routledge International Handbook of Research on Teaching Thinking (pp. 80-91). Abingdon, UK, \& New York, NY: Routledge.

Khemlani, S., Orenes, I., \& Johnson-Laird, P. N. (2012). Negation: A theory of its meaning, representation, and inference. Psychological Review, 109(4), 646-678.

Khemlani, S., Orenes, I., \& Johnson-Laird, P. N. (2014). The negation of conjunctions, conditionals, and disjunctions. Acta Psychologica, 151, 1-7.

López-Astorga, M. (2013). La tesis de Aristóteles y la interpretación bicondicional de los enunciados condicionales. Alpha, 37, 237-248.

López-Astorga, M. (2015a). The formal discipline theory and mental logic. Praxis Filosófica, 41, 11-25.

López-Astorga, M. (2015b). Chrysippus' indemonstrables and mental logic. Croatian Journal of Philosophy, 15(43), 1-15.

López-Astorga, M. (2015c). Evolved mechanisms versus underlying conditional relations. Studies in Logic, Grammar and Rhetoric, 40(53), 241-253.

López-Astorga, M. (2016a). Boethius' Thesis: The connexivist interpretation of the conditional versus its semantic models. Información Filosófica, 13(24), 21-32.

López-Astorga, M. (2016b). Against Philo's interpretation of the conditional: The case of Aristotle's thesis. Agora. Papeles de Filosofía, 35(2), 51-64.

López-Astorga, M. (2016c). The first rule of Stoic logic and its relationship with the indemonstrables. Tópicos. Revista de Filosofía, 50, 9-23.

López-Astorga, M. (2016d). Paradoxical versus modulated conditional inferences: An explanation from the Stoicism. Manuscrito, 39(1), 61-72.

Mates, B. (1953). Stoic Logic. Berkeley and Los Angeles, CA: University of California Press.

McCall, S. (1966). Connexive implication. The Journal of Symbolic Logic, 31, 415-433.

Mueller, I. (1978). An introduction to Stoic logic. In J. M. Rist (Ed.), The Stoics (pp. 1-26). Berkeley, CA: University of California Press.

O’Brien, D. P. (2009). Human reasoning includes a mental logic. Behavioral and Brain Sciences, 32, 96-97.

O'Brien, D. P. (2014). Conditionals and disjunctions in mental-logic theory: A response to Liu and Chou (2012) and to López-Astorga (2013). Universum, 29(2), 221-235.

O'Brien, D. P. \& Li, S. (2013). Mental logic theory: A paradigmatic case of empirical research on the language of thought and inferential role semantics. Journal of Foreign Languages, 36(6), $27-41$.

O’Toole, R. R. \& Jennings, R. E. (2004). The Megarians and the Stoics. In M. D. Gabbay \& J. Woods (Eds.), Handbook of the History of Logic, Volume I. Greek, Indian and Arabic Logic (pp. 397-522). Amsterdam, The Netherlands: Elsevier.

Pfeifer, N. (2012). Experiments on Aristotle's thesis: Towards an experimental philosophy of conditionals. The Monist, 95(2), 223-240.

Ragni, M., Sonntag, T., \& Johnson-Laird, P. N. (2016). Spatial conditionals and illusory inferences. Journal of Cognitive Psychology, 28(3), 348-365. 